\title{
Effectiveness of Teaching Engineering Economics Fundamentals to Undergraduate Engineers Using a Self Taught Computer Tutorial
}

\author{
Donald N. Merino, Ph.D. P.E.; Vishwajeet Rana, MBA MS \\ Stevens Institute of Technology
}

\section{Introduction:}

This article assesses the effectiveness of teaching engineering students using a computer based tutorial. To test the effectiveness of this method of learning the difference in a student's pre and post test scores for individual modules was analyzed. In addition, the computer based tutorial individual modules post test average was compared to the average grade in traditionally (lecture based) courses to assess the learning effectiveness among modes of instruction. The average by module was compared to the overall average to determine the consistency of modules with each other. Lastly, the average grade for all modules was compared to a summary test to determine a student's retention. Fundamentals of Engineering Economics is the subject matter for these self taught computer mediated tutorials.

The students sampled were undergraduate engineering students taking a required engineering economics core course. This course includes a self taught computer tutorial for the fundamentals of engineering economics. Sample size was 129 from two different semesters.

Research results indicate that there is a positive difference that is statistically significant (at 95\% confidence level) between the pre and post tests for all the modules thus indicating that the students learned from these tutorials. The post test grades for individual modules were either significantly different from the traditional method grade $(82 \%)$ or were not different. Since the difference were greater than or equal to zero this indicates that the computer based modules was effective versus the traditional instruction. The average on individual modules was no different than the overall average thus indicating consistency among the modules. Lastly, comparing the results from a summary exam confirmed that the students retained their knowledge.

This study concludes that computer based tutorials are effective for teaching engineering economics fundamentals. Implications of this research are that self taught computer based tutorials could be substituted for traditional instructor based lectures without impairing what a student learns - at least in the case of engineering economics fundamentals. 


\section{Background}

Individual students have different learning abilities and methods of understanding course content. Teaching resources should match the various learning styles of the students. The implementation of different teaching methods like self taught computer mediated tutorials should hopefully be as effective as the traditional teaching methods.

The purpose of this study was to continue to build a body of knowledge on computermediated learning and to derive the impact of additional long term data assimilation on the currently used computer tutorials (Merino, 2002; Merino, April 2003; Merino, June 2003)

The authors believe that the computer mediated tutorials will be equally successful to that of the traditional teaching formats for the quantitative fundamentals. This is comparable to the results concluded by Merino (1989) more than a decade ago and again maintained by Mc Naught, et al. (1995).

\section{The Design of the Study}

To determine that computer mediated learning could provide satisfactory results; a study of undergraduate engineering students taking the core Engineering Economics course was conducted. Data included students from two classes - Spring 2003 and Fall 2003. Students came from all engineering disciplines and the average grades for the two semesters were not significantly different.

The study explored six tutorials based on engineering economics topics (refer Appendix A for the course content). The format of the tutorials was pre-test questions, text regarding respective topics, practice questions and post-test questions. The pre and posttest questions were alike except that the sequence of the questions was changed. After these six tutorials, an online test covering all the material was conducted. The online/summary test had different questions than tutorial but the format remained the same. The students finished three tutorials in first lab/week of the semester and rest three tutorials in second lab/week. The summary test is taken in second lab of Engineering Economics.

There were three types of questions format - true/false, multiple choice and matching columns. The students see the scores of the pre - post test after the submission of post test.

Sample size of this survey is 129 , junior and senior undergraduate engineering students from Stevens Institute of Technology. Numerical data was thus collected six times at the end of each tutorial. The collected data was then entered into a SPSS data sheet and analyzed. 


\section{Study Hypotheses}

The first research question explores the effectiveness of student learning by individual module. The difference in the pre and post-test is the key metric examined. The first hypothesis tests whether the difference is statistically significant. The hypothesis assumes no difference. If there is a positive significant difference then this will mean that the module was effective in increasing student grades and hopefully learning.

Hypothesis H1- Achievement on Individual Modules

Student achievement on the pre test for each individual module will have the same score on the post test.

$$
\text { Null Hypothesis: } \mathrm{H}_{0}:(\mathrm{X} 1=\mathrm{X} 2)
$$

No Difference in mean test scores between the pre and post tests Two tailed t-test $-95 \%$ confidence limit

The second question is whether the difference is positive and whether the student grades for individual modules is equal (or better) than the average grade for students taking the same subjects in traditional courses (e.g. lecture based without computer tutorials).

To satisfy ABET 2000 Continuous Improvement goals the grades by individual topics for this course have been tracked for the last three years. Since this is a required core course for all engineers the sample size is statistically large (over 200 students per year). Using this data base the average grade for these modules was $82 \%$.

Hypothesis H2- Achievement on Individual Modules Greater Than 82\% Student achievement on the post tests for each individual module will be greater than $82 \%$.

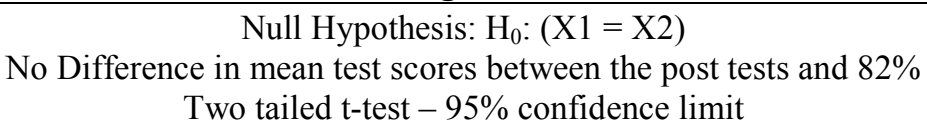

The third question explores the internal consistency of the modules. To determine this difference between the individual modules grades and the summary test grade was examined. That is, were any individual modules better or worse than the whole?

Hypothesis H3- Achievement on Individual Modules versus Overall Average

Student achievement on the post tests for individual modules will have the same score as the Overall average.

Null Hypothesis: $\mathrm{H}_{0}:(\mathrm{X} 1=\mathrm{X} 2)$

No Difference in mean test scores between the individual post tests and overall average Two tailed t-test $-95 \%$ confidence limit

Lastly, the question of retention is examined. This is done by comparing the individual's modules average grade with a summary test grade. This summary test is given at the end after the individual modules. No difference would indicate that the students' retain the knowledge from the modules. A positive significant difference indicates that there was synergy in learning from the modules that helped improve retention. Another explanation could be that the more times a student is tested the higher the score (e.g. there is a learning curve in effect).

Proceedings of the 2004 American Society for Engineering Education Annual Conference \& Exposition Copyright (C) 2004, American Society for Engineering Education 
Hypothesis H4- Achievement on Average of All Modules vs. Summary Test Student achievement on the post tests for the average of all modules will have the same score on the summary test.

Null Hypothesis: $\mathrm{H}_{0}:(\mathrm{X} 1=\mathrm{X} 2)$
No Difference in mean test scores between average for all modules and the Summary test
Two tailed t-test $-95 \%$ confidence limit

\section{Data Analysis and Results}

Appendix B is the result for Hypothesis 1. Each individual module post-test grade was statistically different than the pre-test at the $95 \%$ level of confidence. Given that all the differences were positive this indicates that the modules were effective in increasing the students' grades and hopefully their knowledge of this material.

Table 1: Student Grades on Modules Post-Tests are Different than the Pre-Test

\begin{tabular}{|c|c|c|c|c|c|c|c|}
\hline Modules $>$ & A & B & C & D & E & F & A - F \\
\hline Significance & YES & YES & YES & YES & YES & YES & YES \\
\hline
\end{tabular}

Appendix $\mathrm{C}$ is the result for Hypothesis 2. Individual modules grades for $\mathrm{A}-\mathrm{D}$ and $\mathrm{F}$ were significantly different from the traditional teaching method average of $82 \%$. This indicates that students' grades for these computer based self taught modules were slightly better than those who took these topics in the traditional teaching mode (lectures). For module $\mathrm{E}$ there was no significant difference indicating that the computer tutorials were equal to traditional learning. Also, the average for A-F was positive and significantly different than $82 \%$ indicating that on average these computer tutorials were slightly more effective than traditional lecture teaching.

Table 2: Student Grades on Modules Post-Tests are Equal to or Greater than $82 \% \mathrm{t}$

\begin{tabular}{|c|c|c|c|c|c|c|c|}
\hline Modules $>$ & A & B & C & D & E & F & A - F \\
\hline Significance & YES $>$ & YES & YES & YES & NO & YES & YES \\
\hline Greater or Equal & Greater & Greater & Greater & Greater & Equal & Greater & Greater \\
\hline
\end{tabular}

Appendix D is the result for Hypothesis 3. Individual modules post-test averages were not significantly different than the overall average. This indicates that there was consistency among the modules, given grades as the measure.

Table 3: Student Grades on Modules Post-Tests versus Summary Test Post-Test

\begin{tabular}{|c|c|c|c|c|c|c|}
\hline Modules $>$ & A & B & C & D & E & F \\
\hline Significance & NO & NO & NO & NO & NO & NO \\
\hline
\end{tabular}

Appendix E is the result for Hypothesis 4. There was a slight positive difference which was not statistically significant. This indicates that the students retained the knowledge from the modules and that is also some learning curve effect and/or synergy in this exercise. 
Table3. Student Grades: Overall Average versus Summary Test.

\begin{tabular}{|c|c|}
\hline Modules $>$ & A-F Overall Aver vs. Summary Test \\
\hline Difference / Significance & Positive / NO \\
\hline
\end{tabular}

\section{Implications for Teaching and Future Research}

Computer based tutorials provide the instructor an opportunity and flexibility to change the way the course will be delivered. Computer based tutorials could be used as homework or labs and could free some lecture sessions for other material and/or practicums/workshops and/or quest speakers.

Computer based tutorials could also be used as a prerequisite for the course. These could be considered ramps. Computer based tutorials could be used to generate interest in or awareness in a particular subject.

Lastly, these self taught computer based modules provide one more data point to assess student learning. This is particularly important for ABET 2000 assessment and to judge Continues Process Improvements. These tutorials can be web based and can be easily used in distance learning courses.

Additionally, the self taught and imbedded grading is helpful in testing proficiency for different constituencies. One constituency is graduate engineers who are the "product" of an engineering curriculum. Knowing what graduate engineers know is helpful in setting the goals / competencies for Engineering Economics.

\section{Bibliography}

\footnotetext{
${ }^{1)}$ Merino, D.N. (June 16, 1989).

"Effectiveness of Computer Based Problem Solving in Teaching Engineering Economics", ASEE

Conference Proceedings, American Society of Engineering Education (ASEE), Session 1639, pg. 293-295; refereed paper.

${ }^{2)}$ McNaught, Carmel; Grant, Heather; Fritze, Paul; Barton, Janet; McTigue, Peter; Prosser, Robert (1995, November).

"The Effectiveness of Computer-Assisted Learning in the Teaching of Quantitative Volumetric Analysis Skills in a First-Year University Course", Journal of Chemical Education, Vol. 72, No. 11,pg. 1003 - 1107.

3) Merino, Donald N. and Abel, Kate D. (2003, June). "Evaluating the Effectiveness of Using Computer Tutorials to Teach Basic Accounting”, American Society for Engineering Education (ASEE) Annual Conference and Exposition Proceedings, Nashville, Tennessee.

4) Merino, Donald N. and Abel, Kate D. (2003. April), “Computer Tutorials vs. Traditional Lecturing: Which is a More Effective Learning Environment?” Journal of Engineering Education, Vol. 92, No. 2, pg. 189.
} 


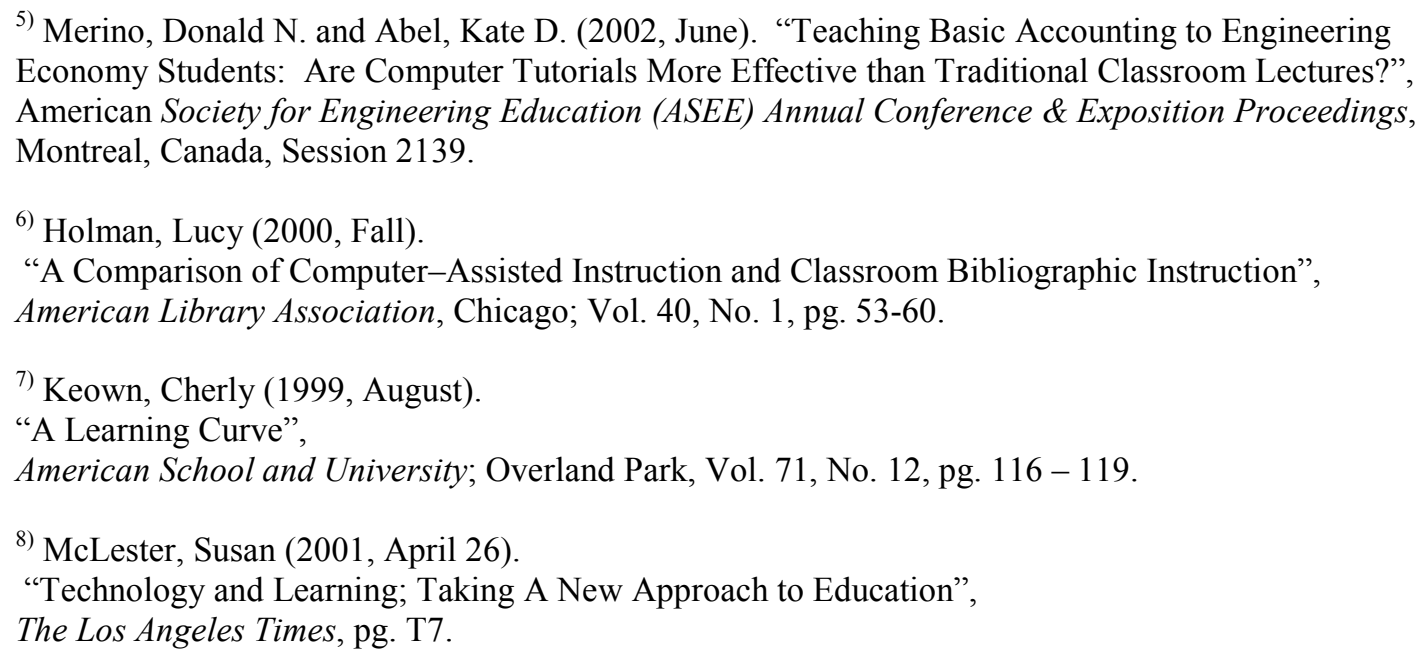

\section{Authors Profile:}

Dr. Donald N. Merino is the Alexander Crombie Humphreys Professor of Engineering Economics at Stevens Institute of Technology. He teaches Engineering Economics, Project Management, Total Quality Management, Decision Sciences, Strategic Business Planning and Concurrent Engineering. He won the Morton Distinguished Teaching Award for full professors at Stevens. He was PI to develop a concurrent engineering graduate program. His book, "The Selection for Capital Projects", was published by John Wiley in their Engineering and Technology Management series. $\mathrm{He}$ is the Emeritus Founding Director of the undergraduate Bachelor of Engineering in Engineering Management (BEEM) and the Executive Masters of Technology Management (EMTM) programs. He is the Founding Director of the Masters of Engineering in Engineering Management (MEEM) program. Dr. Merino received two Centennial certificates from the American Society of Engineering Education (ASEE) in Engineering Economics and Engineering Management. He was elected a Fellow of ASEE in 2002. He is past chair of the Engineering Management Division (EMD) and Engineering Economy Division (EED) of ASEE. Dr. Merino was awarded the B. Sarchet Award from the ASEE/EMD and the American Society of Engineering Management (ASEM). He is a Fellow and past president of ASEM. Dr. Merino has 25 years of industrial experience in positions of increasing managerial responsibilities. Since joining academe 20 years ago, he has published more than 30 refereed journal articles and conference papers and over 50 research reports.

Vishwajeet Rana is a doctoral student in Engineering Management. He has three years of research experience in Technology Management and done his MBA, MS in information system.

\section{$\underline{\text { Appendix A-Topics covered in the tutorials }}$}

\section{A: CASH FLOW PATTERNS}

- Cash Flow Streams.

- Cash Flow Conventions.

- Cash Flow Patterns.

- Continuous Cash Flows

- Loans \& Funding.

B: UNDISCOUNTED FIGURE OF MERIT

- Payback period

- Payback Advantages and Disadvantages.

- Return on Investments
- Return On Average Investments.

C: RATES OF RETURN

- Time Value of Money

- Simple and Compound Interest

- Periodic, Nominal and Effective Interest Rates

- Continuous Compounding

- Compounding and Discounting

\section{D: EQUIVALENCE RELATIONSHIP}

- Equivalent Cash Flows.

Proceedings of the 2004 American Society for Engineering Education Annual Conference \& Exposition Copyright (C) 2004, American Society for Engineering Education 
- Rate of Returns.

- Discrete Cash Flow Factors.

- Continuous Cash Flow factors.

- Manipulating Rate of Return Factors

E: THE THREE WORTHS

- The Three Worths.

- The Difference Between the three Worths.
- Calculation of The Three Worths.

F: Capitalized Cost and Cost Recovery

- Capitalized Cost (CC)

- Capital Recovery (CR)

\section{$\underline{\text { Appendix - B - Hypothesis 1- Achievement on Individual Modules }}$}

\begin{tabular}{|l|c|c|c|c|c|c|r|}
\hline \multicolumn{1}{|c|}{ Modules } & A & B & C & D & E & F & A - F \\
\hline Pre-Test & & & & & & & \\
\hline Mean & .8050 & .7551 & .7289 & .7707 & 6373 & .6737 & .7284 \\
\hline Std. Dev. & .1585 & .1470 & .1454 & .1796 & .1455 & .1640 & .1567 \\
\hline Std. Error Mean & .0147 & .0137 & .0135 & .0169 & .0136 & .0155 & .0146 \\
\hline Post-Test & & & & & & & \\
\hline Mean & .9435 & .9171 & .9203 & .9238 & .8253 & .8786 & .9014 \\
\hline Std. Dev. & .0756 & .0839 & .0682 & .0699 & .0987 & .1116 & .0847 \\
\hline Std. Error Mean & .0070 & .0078 & .0063 & .0066 & .0092 & .0105 & .0079 \\
\hline $\begin{array}{l}\text { Diff. in Means: } \\
\text { Pre- Post }\end{array}$ & .1385 & .1620 & .1914 & .1531 & .1880 & .2049 & .1730 \\
\hline
\end{tabular}

$\underline{\text { Appendix - C - Hypothesis 2- Individual Modules Post Test }>82 \%}$

\begin{tabular}{|l|c|c|c|c|c|c|c|}
\hline \multicolumn{1}{|c|}{ Modules } & $\mathbf{A}$ & $\mathbf{B}$ & $\mathbf{C}$ & $\mathbf{D}$ & $\mathbf{E}$ & $\mathbf{F}$ & $\mathbf{A}-\mathbf{F}$ \\
\hline Post Test Mean & .9435 & .9171 & .9203 & .9238 & .8253 & .8786 & .9014 \\
\hline Std. Dev. & .0756 & .0839 & .0682 & .0699 & .0987 & .1116 & .0847 \\
\hline Traditional Mean & .8200 & .8200 & .8200 & .8200 & .8200 & .8200 & .8200 \\
\hline Std. Dev. & .0800 & .0800 & .0800 & .0800 & .0800 & .0800 & .0800 \\
\hline $\begin{array}{l}\text { Diff. in Means: } \\
\text { Pre - Post }\end{array}$ & .1235 & .0971 & .1003 & .1038 & .0053 & .0586 & .0814 \\
\hline & & & & & & & \\
\hline t value & 17.675 & 12.465 & 15.833 & 15.789 & .569 & 5.652 & 12.418 \\
\hline Degrees of freedom & 116 & 115 & 115 & 112 & 113 & 112 & 128 \\
\hline Significance & Yes & Yes & Yes & Yes & Yes & Yes & Yes \\
\hline
\end{tabular}

\section{$\underline{\text { Appendix - D - Hypothesis 3 - Achievement on Individual Modules vs. Overall Average }}$}

\begin{tabular}{|c|c|c|c|c|c|c|}
\hline Paired pre-post test & A & B & C & D & E & F \\
\hline t value & -10.563 & -11.047 & -13.948 & -9.958 & -12.860 & -13.303 \\
\hline Degrees of freedom & 116 & 115 & 115 & 112 & 113 & 111 \\
\hline Significance & .000 & .000 & .000 & .000 & .000 & .000 \\
\hline
\end{tabular}

\section{$\underline{\text { Appendix - E - Hypothesis 4 - Average of Modules vs. Summary Test }}$}

\begin{tabular}{|l|l|l|}
\hline & Mean & Std. Dev. \\
\hline Avg. Post-Test Modules & .9014 & .0847 \\
\hline Summary Test on All Modules & .8885 & .1179 \\
\hline Difference & .0129 & .0332 \\
\hline
\end{tabular}

Proceedings of the 2004 American Society for Engineering Education Annual Conference \& Exposition Copyright (C) 2004, American Society for Engineering Education 